\title{
Perfil da pessoa idosa vítima de violência intrafamiliar de um centro integrado de proteção e defesa de direitos em tempos de pandemia
}

\author{
Profile of older people victims of domestic violence in an integrated center for protection and \\ defense of rights in times of pandemic
}

Alisilvia Leão Pedroso' $\mathbb{1 D}$

Seldon Rodrigues Duarte Júnior ${ }^{1}$ Nathália França de Oliveiral ${ }^{\mathbb{D}}$

\section{Resumo}

Objetivo: comparar o perfil das pessoas idosas vítimas de violência intrafamiliar atendidas em um Centro Integrado de Proteção e Defesa de Direitos, em Manaus, Amazonas, Brasil, no ano de 2019 e no contexto de pandemia. Método: Estudo analítico transversal dos atendimentos referentes à pessoa idosa vítima de violência intrafamiliar realizados no período de janeiro de 2019 a dezembro de 2020. Foi aplicada análise descritiva e comparativa com o teste do $\chi^{2}$, ao nível de significância de $5 \%$, na distribuição das características das vítimas, das ocorrências e dos atendimentos. Resultados: Houve aumento de quase $25 \%$ nos atendimentos às vítimas de violência intrafamiliar no ano de $2020 \mathrm{em}$ comparação com 2019. O perfil aponta para uma maioria do sexo feminino $(58,9 \%)$, com idade entre 60 e 80 anos (78,9\%), viúvos/casados/união estável (60,0\%), pardos (71,0\%), católicos (56,0\%), com ensino fundamental (37,7\%), aposentados/pensionistas $(55,6 \%)$ e residentes nas zonas norte $(23,3 \%)$ e sul $(19,9 \%)$ de Manaus. A violência que mais acometeu os idosos atendidos foi a intimidação/perturbação (34,5\% em 2019 e $33,2 \%$ em 2020), perpetrada pelos filhos (66,4\% em 2019 e 69,0\% em 2020) com cerca de $7,0 \%$ das situações sob uso de álcool e/ou drogas. Houve redução de quase $9,0 \%$ dos atendimentos presenciais realizados em $2020(p<0,01)$. As ocorrências demandaram o encaminhamento principalmente à delegacia especializada (40\%). Conclusão: Foram encontradas diferenças significativas nas características das ocorrências e dos atendimentos entre os anos o que reforça a influência da pandemia e a importância da atuação do sistema de garantias de direito da pessoa idosa.

\footnotetext{
Universidade do Estado do Amazonas, Programa de Pós-Graduação em Segurança Pública, Cidadania e Direitos Humanos. Manaus, AM, Brasil.
}

Os autores declaram não haver conflito na concepção deste trabalho.

Não houve financiamento para a execução deste trabalho.

Palavras-chave: Idoso. Violência. Maus-Tratos ao Idoso. Política Pública. 


\section{Abstract}

Objective: to compare the profile of older people victim of intra-family violence attended at an Integrated Center for the Protection and Defense of Rights, in Manaus, Amazonas, Brazil, in 2019 and in the context of a pandemic. Method: Cross-sectional analytical study of care for older people victims of intra-family violence carried out from January 2019 to December 2020. Descriptive and comparative analysis was applied with the $\chi^{2}$ test, at a significance level of $5 \%$, in the distribution of characteristics of victims, occurrences and care provided. Results: There was an increase of almost $25 \%$ in the care provided to victims of intra-family violence in 2020 compared to 2019 . The profile points to most of the female sex $(58.9 \%)$, aged between 60 and 80 years $(78.9 \%)$, widowed/married/ stable union $(60.0 \%)$, brown $(71.0 \%)$, Catholic $(56.0 \%)$, with elementary education $(37.7 \%)$, retired/pensioners $(55.6 \%)$ and residents in the northern $(23.3 \%)$ and southern $(19.9 \%)$ zones of Manaus. The violence that most affected the older people assisted was intimidation/disruption (34.5\% in 2019 and $33.2 \%$ in 2020), perpetrated by their children (66.4\% in 2019 and $69.0 \%$ in 2020) with about $7.0 \%$ of situations under alcohol and/or drug use. There was a reduction of almost $9.0 \%$ in face-to-face care provided in 2020 ( $\mathrm{p}<0.01)$. The occurrences demanded referral mainly to the specialized police station (40\%). Conclusion: Significant differences were found in the characteristics of occurrences and care between years, which reinforces the influence of the pandemic and the importance of the performance of the system of guarantees of rights for older people.

\section{INTRODUÇ̃̃O}

A transição demográfica é um dos fenômenos estruturais mais importantes que tem marcado a economia e a sociedade brasileira desde a segunda metade do século passado ${ }^{1}$. Segundo estimativas populacionais, houve um aumento de quase 5,0\% da população idosa no Amazonas no ano de 2020, em comparação ao ano anterior. Manaus concentra cerca de 57,0\% do total de idosos residentes no estado $^{2}$.

Com o aumento da proporção de idosos na população, entende-se que um conjunto de políticas públicas estão condicionadas ${ }^{3}$ ao crescimento da consciência social, a idade cronológica e suas diferentes etapas, e estes passam a ser utilizados como princípios norteadores de novos direitos e deveres, sobretudo no caso de grupos mais vulneráveis ${ }^{4}$.

De acordo com Minayo e Souza ${ }^{5}$, a vulnerabilidade social e etária torna os idosos mais expostos à ocorrência das violências, e estas podem se manifestar de forma: (a) estrutural, aquela que ocorre pela desigualdade social e é naturalizada nas manifestações de pobreza, de miséria e de discriminação; (b) interpessoal nas formas de comunicação e de interação cotidiana e (c) institucional, na aplicação ou omissão na gestão das políticas sociais pelo Estado e pelas instituições de assistência, maneira privilegiada de reprodução das relações assimétricas de poder, de domínio, de menosprezo e de discriminação.

Para a Organização Mundial da Saúde (OMS) ${ }^{6}$, a violência se constitui em uso intencional da força física ou do poder, real ou em ameaça, contra si próprio ou contra outra pessoa, grupo ou comunidade, resultando ou na possibilidade de lesão, morte, dano psicológico, deficiência de desenvolvimento ou privação, ou o conjunto destes. Quanto a sua classificação, as violências podem ser enquadradas como: abuso físico, psicológico, sexual, financeiro, negligência, abandono e autonegligência.

A violência intrafamiliar é uma questão de grande amplitude e complexidade cujo enfrentamento envolve profissionais de diferentes campos de atuação, requerendo, por conseguinte, uma efetiva mobilização de diversos setores do governo e da sociedade civil. Tal mobilização visa, em especial, fortalecer e potencializar as ações e serviços na perspectiva de uma nova atitude, compromisso e colaboração em relação ao problema ${ }^{7}$. 
O isolamento social em decorrência da pandemia de COVID-19 gerou impacto sobre a ocorrência de violência doméstica e familiar. Embora as informações sejam ainda incipientes, notícias divulgadas na mídia e relatórios de organizações internacionais apontam para o aumento desse tipo de violência. $\mathrm{Na}$ China, os registros policiais de violência doméstica triplicaram durante a epidemia. $\mathrm{Na}$ Itália, na França e na Espanha também foi observado aumento na ocorrência de violência doméstica após a implementação da quarentena domiciliar obrigatória ${ }^{8}$. Entretanto, Moraes et al. ${ }^{9}$ afirmam que esse isolamento social gera várias repercussões negativas, dentre elas o aumento da violência intrafamiliar contra crianças, adolescentes, mulheres e idosos.

Para assegurar o acesso ao sistema de garantia de direitos a pessoa idosa e a prevenção da ocorrência dessas violências torna-se fundamental a implementação de políticas públicas que respondam às necessidades geradas pelas rápidas transformações demográficas. Diferentemente das sociedades que envelheceram em ritmo mais lento e se adaptaram paulatinamente a essa situação, o Brasil enfrenta a exigência de ampliar o entendimento das implicações de ordem demográfica, econômica e social do processo de envelhecimento e organizar políticas para enfrentá-las ${ }^{10}$.

Deste modo, diante do exposto, e entendendo a importância de atentar para a violência intrafamiliar contra a pessoa idosa em tempos de pandemia, com a finalidade de compreender como as instituições públicas de proteção e garantias de direito da pessoa idosa têm atuado frente a esse contexto, o objetivo deste artigo é comparar o perfil da pessoa idosa vítima de violência intrafamiliar atendida em um Centro Integrado de Proteção e Defesa de Direitos, em Manaus, Amazonas, Brasil, no ano de 2019 e em contexto de pandemia da COVID-19, no ano de 2020.

\section{MÉTODO}

Trata-se de um estudo analítico do tipo transversal dos atendimentos realizados a pessoa idosa, com idade igual ou superior a 60 anos, vítimas de violência intrafamiliar do Centro Integrado de
Proteção e Defesa dos Direitos da Pessoa Idosa (CIPDI) situado na cidade de Manaus, Amazonas, Brasil. Os dados utilizados no estudo se referem aos atendimentos realizados entre os meses de janeiro de 2019 a dezembro de 2020, gerados pelos Relatórios Oficiais Mensais de Atendimento solicitados em outubro de 2020.

O CIPDI foi implementado em 2007 para oferecer atendimento qualificado e multisetorial à pessoa idosa vítima de discriminação ou violência, coordenado pelo Conselho de Desenvolvimento Humano $(\mathrm{CDH})$ e implantado pela Secretaria de Estado de Segurança Pública (SSP), em parceria com a Secretaria de Assistência Social (SEAS). A assistência realizada conta com a disponibilidade de profissionais $\mathrm{da}$ segurança, assistentes sociais e psicólogos, com a finalidade de dar suporte psicossocial aos idosos vítimas de violência intrafamiliar.

Para traçar o perfil dos atendimentos, foram estudadas as seguintes variáveis: caracterização das vítimas (sexo, idade, estado civil, raça/cor, religião, escolaridade, situação econômica e zona de residência); caracterização da ocorrência (tipo de violência, vínculo com a vítima e se no momento da ocorrência o agressor estava sob uso de drogas psicoativas); como também, os encaminhamentos e atendimentos viabilizados aos idosos na instituição em destaque.

$\mathrm{Na}$ análise estatística comparativa, as diferenças das características das vítimas, das ocorrências e dos atendimentos entre os anos de análise 2019 (prépandemia) e 2020 (contexto de pandemia) foram testadas pelo teste qui-quadrado $\left(\chi^{2}\right)$, ao nível de significância de 5\%.

O estudo não foi submetido ao Comitê de Ética em Pesquisa por utilizar dados secundários, de domínio público, disponibilizados no site do Sistema de Informações Governamentais do Amazonas (e-SIGA). Assim como, o acesso aos Relatórios Oficiais de Atendimento foi solicitado à Secretaria de Estado de Justiça, Direitos Humanos e Cidadania (SEJUSC) para fins de produção científica. Acrescenta-se que os dados não apresentam qualquer informação referente à identificação dos casos atendidos, em consonância com as normas e diretrizes da Resolução 510/2016 do Conselho Nacional de Saúde. 


\section{RESULTADOS}

Durante o período de janeiro de 2019 a dezembro de 2020, foram notificados 5.365 casos de violência intrafamiliar envolvendo idosos atendidos no CIPDI, sendo 2.385 no ano de 2019 e 2.980 em 2020 . Houve aumento de $24,9 \%$ das ocorrências no ano de 2020 , primeiro ano de pandemia, em comparação ao ano anterior. Os meses de maior frequência das ocorrências no ano de 2019 foram os de janeiro (9,5\%) e julho (11,7\%), respectivamente. No entanto, em 2020, o mês de abril apresentou uma queda de quase $97 \%$ nas ocorrências em comparação ao mesmo período do ano anterior. Ainda no ano de 2020, verificou-se que os atendimentos de idosos vítimas de violência intrafamiliar duplicou entre os meses de outubro a dezembro quando em comparação ao aos mesmos meses de 2019 (Figura 1).

A descrição das características sociodemográficas dos casos de violência intrafamiliar envolvendo idosos atendidos pelo CIPDI, segundo ano de atendimento é apresentada na Tabela 1. Considerando o conjunto de ocorrências, em quase $60 \%$ dos casos era do sexo feminino. Observou-se que em mais de $80 \%$ dos idosos acometidos tinha menos de 80 anos de idade.

Ainda na Tabela 1, do total de casos de violência intrafamiliar atendidos, 60\% eram viúvos, casados ou em união estável, com mais de 70\% dos casos de raça/cor parda. A maioria dos idosos se autodeclararam católicos e em ambos os anos de análise, o ensino fundamental (incompleto ou completo) predominou entre o nível escolar das vítimas. Dentre os atendimentos realizados, em mais de $50,0 \%$ se referiam a aposentados ou pensionistas. A zona de residências dessas vítimas se concentrou entre as regiões norte e sul da capital do estado do Amazonas. Em relação a análise comparativa, constatou-se diferença nas características referentes ao estado civil, escolaridade, situação econômica e zona de residência entre os anos de $(p<0,05)$.

As características das ocorrências de violência intrafamiliar são apresentadas na Tabela 2. Os principais tipos de violência perpetradas contra os idosos em ambos os anos de análise foram a intimidação/perturbação e a negligência, com o acometimento de mais de $50 \%$ dos casos. No entanto, constatou-se redução dos casos registrados das ocorrências de maus-tratos, abuso financeiro e ameaça verbal no ano de pandemia. A ocorrência de algumas violências não identificadas no ano de 2019, como a agressão verbal, física, autonegligência, ameaça de morte, abandono e discriminação, também foram identificadas e confirmadas pela diferença estatisticamente significativa entre os anos de análise $(p<0,05)$. Em mais de $2 / 3$ das situações de violência intrafamiliar acompanhados pelo centro, os filhos foram os principais agressores e o uso de álcool e outras drogas pelos perpetradores durante a ocorrência apresentou discreto aumento no ano de pandemia.

A Tabela 3 apresenta a descrição dos encaminhamentos e atendimentos realizados aos idosos vítimas de violência intrafamiliar pelo CIPDI. Nos anos de 2019 e 2020, mais de 50\% dos atendimentos demandou algum tipo de encaminhamento, com destaque para a Delegacia Especializada de Crime Contra o Idoso. No ano de 2020, primeiro ano da pandemia de COVID-19, houve um aumento de $54,2 \%$ da demanda por outros atendimentos externos realizados pelo CIPDI, com destaque para as visitas domiciliares, mediação de conflitos e visitas técnicas. No entanto, verificou-se que os serviços direcionados a avaliação psicológica tiveram oferta reduzida à menos que a metade no ano de 2020, em comparação com o ano anterior. 


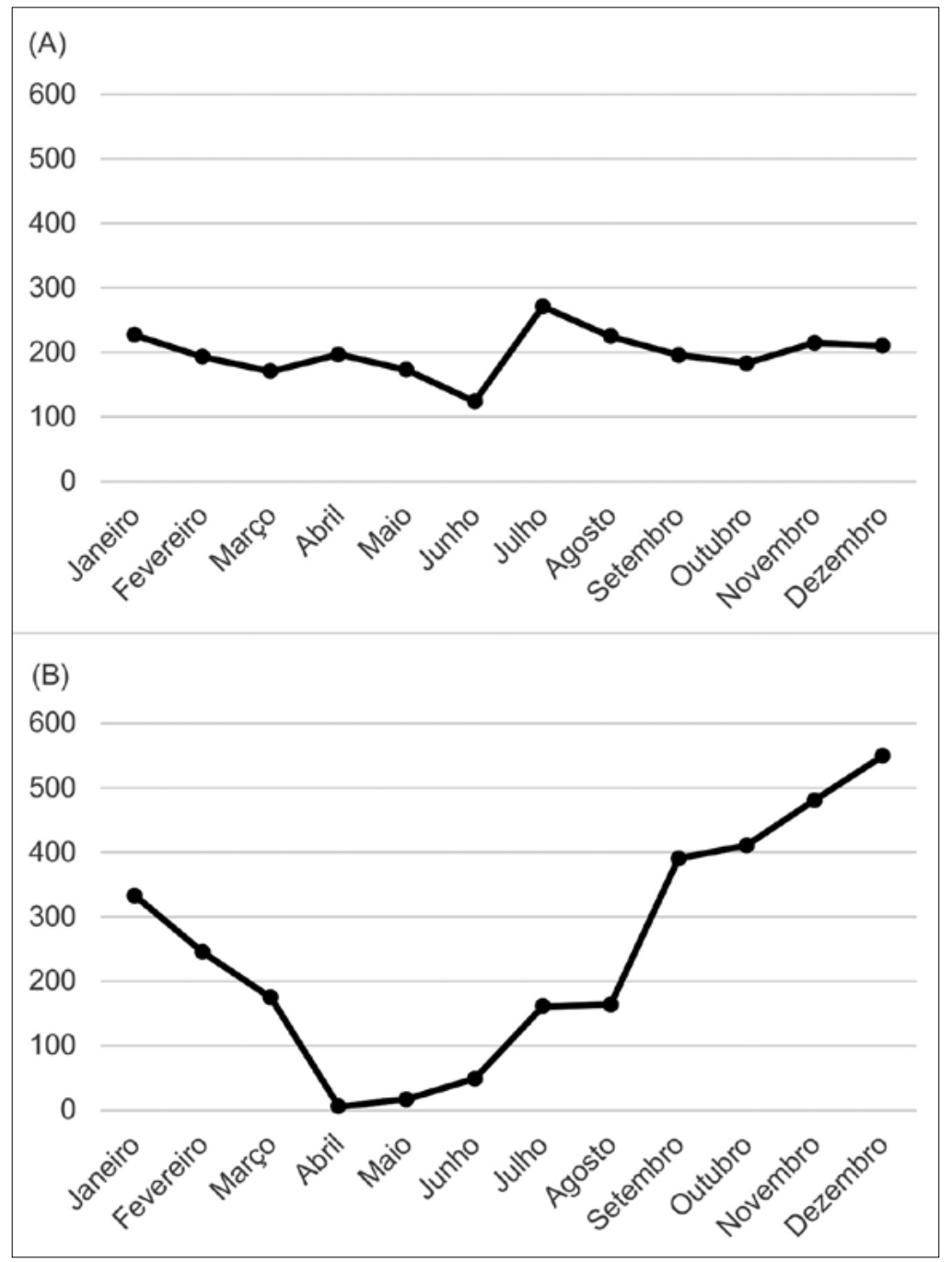

Fonte: Sistema de Informações Governamentais do Amazonas (e-SIGA).

Figura 1. Casos de violência intrafamiliar contra a pessoa idosa atendidas pelo Centro Integrado de Proteção e Defesa dos Direitos da Pessoa Idosa. Manaus, AM, Brasil (A) 2019 - (B) 2020.

Tabela 1. Descrição das características sociodemográficas dos idosos vítimas de violência intrafamiliar atendidos por um Centro Integrado de Proteção e Defesa dos Direitos da Pessoa Idosa ( $N=5.365)$. Manaus, AM, Brasil, $2019-2020$.

\begin{tabular}{lllll}
\hline Variáveis & $\begin{array}{l}\text { Total } \\
\mathrm{n}(\%)\end{array}$ & $\begin{array}{l}2019 \\
\mathrm{n}(\%)\end{array}$ & $\begin{array}{l}2020 \\
\mathrm{n}(\%)\end{array}$ & $p$-valor \\
\hline $\begin{array}{l}\text { Sexo } \\
\text { Feminino }\end{array}$ & $3.159(58,9)$ & $1.431(60,0)$ & $1.728(58,0)$ & 0,136 \\
Masculino & $2.206(41,1)$ & $954(40,0)$ & $1.252(42,0)$ & \\
\hline $\begin{array}{l}\text { Faixa etária (anos) } \\
60-70\end{array}$ & $2.555(47,6)$ & $1.184(49,6)$ & $1.371(46,0)$ & 0,060 \\
$71-80$ & $1.679(31,3)$ & $725(30,4)$ & $954(32,0)$ & $536(18,0)$ \\
$81-90$ & $924(17,2)$ & $388(16,3)$ & $119(4,0)$ & \\
91 e mais & $207(3,9)$ & $88(3,7)$ & &
\end{tabular}


Continuação da Tabela 1

\begin{tabular}{|c|c|c|c|c|}
\hline Variáveis & $\begin{array}{l}\text { Total } \\
\mathrm{n}(\%)\end{array}$ & $\begin{array}{l}2019 \\
\mathrm{n}(\%)\end{array}$ & $\begin{array}{l}2020 \\
\mathrm{n}(\%)\end{array}$ & $p$-valor \\
\hline \multicolumn{5}{|l|}{ Estado civil } \\
\hline Viúvo & $1.609(30,0)$ & $781(32,7)$ & $828(27,8)$ & \multirow{4}{*}{$<0,01^{*}$} \\
\hline Casado/união estável & $1.610(30,0)$ & $543(22,8)$ & $1.067(35,8)$ & \\
\hline Solteiro & $966(18,0)$ & $495(20,8)$ & $471(15,8)$ & \\
\hline Divorciado/separado & $1.180(22,0)$ & $566(23,7)$ & $614(20,6)$ & \\
\hline \multicolumn{5}{|l|}{ Raça/cor } \\
\hline Pardo & $3.809(71,0)$ & $1.694(71,0)$ & $2.115(71,0)$ & \multirow{3}{*}{0,980} \\
\hline Não pardo & $1.551(28,9)$ & $689(28,9)$ & $862(28,9)$ & \\
\hline Sem informações & $5(0,1)$ & $2(0,1)$ & $3(0,1)$ & \\
\hline \multicolumn{5}{|l|}{ Religião } \\
\hline Católico & $3.004(56,0)$ & $1.336(56,0)$ & $1.668(56,0)$ & \multirow{4}{*}{1,000} \\
\hline Evangélico & $1.717(32,0)$ & $763(32,0)$ & $954(32,0)$ & \\
\hline Outras & $54(1,0)$ & $24(1,0)$ & $30(1,0)$ & \\
\hline Sem informações & $590(11,0)$ & $262(11,0)$ & $328(11,0)$ & \\
\hline \multicolumn{5}{|l|}{ Escolaridade } \\
\hline Analfabeto & $1.019(19,0)$ & $453(19,0)$ & $566(19,0)$ & \multirow{6}{*}{$<0,01^{*}$} \\
\hline Alfabetizado & $898(16,7)$ & $451(18,9)$ & $447(15,0)$ & \\
\hline Fund. incompleto/completo & $2.019(37,7)$ & $887(37,1)$ & $1.132(38,0)$ & \\
\hline Médio incompleto/completo & $1.020(19,0)$ & $453(19,0)$ & $567(19,0)$ & \\
\hline Superior incompleto/completo & $357(6,6)$ & $119(6,9)$ & $238(8,0)$ & \\
\hline Outros/sem informação & $52(1,0)$ & $22(0,9)$ & $30(1,0)$ & \\
\hline \multicolumn{5}{|l|}{ Situação econômica } \\
\hline Aposentados & $2.447(45,6)$ & $1.076(45,1)$ & $1.371(46,0)$ & \multirow{7}{*}{$<0,01^{*}$} \\
\hline Pensionistas & $538(10,0)$ & $240(10,1)$ & $298(10,0)$ & \\
\hline BPC & $1.166(21,7)$ & $510(21,4)$ & $656(22,0)$ & \\
\hline Autônomos & $230(4,3)$ & $111(4,6)$ & $119(4,0)$ & \\
\hline Sem renda & $452(8,4)$ & $243(10,2)$ & $209(7,0)$ & \\
\hline Outros & $474(8,8)$ & $177(7,4)$ & $297(10,0)$ & \\
\hline Sem informações & $58(1,1)$ & $28(1,2)$ & $30(1,0)$ & \\
\hline \multicolumn{5}{|l|}{ Zona de residência } \\
\hline Norte & $1.253(23,3)$ & $538(22,6)$ & $715(24,0)$ & \multirow{8}{*}{$0,02 *$} \\
\hline Sul & $1.068(19,9)$ & $472(19,8)$ & $596(20,0)$ & \\
\hline Leste & $1.001(18,7)$ & $465(19,5)$ & $536(18,0)$ & \\
\hline Oeste & $729(13,6)$ & $342(14,3)$ & $387(13,0)$ & \\
\hline Centro-sul & $614(11,4)$ & $287(12,0)$ & $327(11,0)$ & \\
\hline Centro-oeste & $470(8,8)$ & $202(8,5)$ & $268(9,0)$ & \\
\hline Rural & $141(2,6)$ & $52(2,2)$ & $89(3,0)$ & \\
\hline Outros municípios & $89(1,7)$ & $27(1,1)$ & $62(2,1)$ & \\
\hline
\end{tabular}

Teste qui-quadrado de Pearson; ${ }^{*}$-valor $<0,05$; BPC: Benefício de Prestação Continuada. Fonte: Sistema de Informações Governamentais do Amazonas (e-SIGA). 
Tabela 2. Descrição das características das ocorrências de violência intrafamiliar contra idosos atendidos por um Centro Integrado de Proteção e Defesa dos Direitos da Pessoa Idosa (N=5.365). Manaus, AM, Brasil, 2019 - 2020.

\begin{tabular}{|c|c|c|c|}
\hline Variáveis & $\begin{array}{l}2019 \\
\mathrm{n}(\%)\end{array}$ & $\begin{array}{l}2020 \\
\mathrm{n}(\%)\end{array}$ & $p$-valor \\
\hline \multicolumn{4}{|c|}{ Tipo de violência intrafamiliar } \\
\hline Abandono & $0(0,0)$ & $15(0,5)$ & \multirow{12}{*}{$<0,01 *$} \\
\hline Abuso financeiro & $190(8,0)$ & $117(3,9)$ & \\
\hline Agressão psicológica & $218(9,1)$ & $268(9,0)$ & \\
\hline Agressão verbal & $0(0,0)$ & $185(6,2)$ & \\
\hline Agressão física & $0(0,0)$ & $157(5,3)$ & \\
\hline Ameaça de morte & $0(0,0)$ & $142(4,8)$ & \\
\hline Ameaça verbal & $331(13,9)$ & $200(6,7)$ & \\
\hline Autonegligência & $0(0,0)$ & $77(2,6)$ & \\
\hline Discriminação & $0(0,0)$ & $10(0,3)$ & \\
\hline Intimidação/perturbação & $823(34,5)$ & $989(33,2)$ & \\
\hline Maus-tratos & $107(4,5)$ & $74(2,5)$ & \\
\hline Negligência & $716(30,0)$ & $746(25,0)$ & \\
\hline \multicolumn{4}{|l|}{ Vínculo com a vítima } \\
\hline Filho(a) & $1.584(66,4)$ & $2.055(69,0)$ & \multirow{3}{*}{$<0,01 *$} \\
\hline Própria pessoa & $343(14,4)$ & $341(11,4)$ & \\
\hline Outros familiares & $458(19,2)$ & $584(19,6)$ & \\
\hline \multicolumn{4}{|c|}{ Uso de substâncias psicoativas durante a ocorrência } \\
\hline Álcool & $45(1,9)$ & $62(2,1)$ & \multirow{4}{*}{0,118} \\
\hline Outras drogas & $23(0,9)$ & $50(1,7)$ & \\
\hline Álcool e outras drogas & $76(3,2)$ & $105(3,5)$ & \\
\hline Não se aplica & $2.241(94,0)$ & $2.763(92,7)$ & \\
\hline
\end{tabular}

Teste qui-quadrado de Pearson; *p-valor $<0,05$. Fonte: Sistema de Informações Governamentais do Amazonas (e-SIGA).

Tabela 3. Descrição dos atendimentos realizados junto aos idosos vítimas de violência intrafamiliar atendidos por um Centro Integrado de Proteção e Defesa dos Direitos da Pessoa Idosa (N=5.365). Manaus, AM, Brasil, $2019-2020$.

\begin{tabular}{llll}
\hline Variáveis & $\begin{array}{l}2019 \\
\mathrm{n}(\%)\end{array}$ & $\begin{array}{l}2020 \\
\mathrm{n}(\%)\end{array}$ & $p$-valor \\
\hline Encaminhamentos & & & \\
Casa da Cidadania/DPE & $484(20,3)$ & $587(13,0)$ & \\
Núcleo Especializado/DPE & $487(20,4)$ & $566(19,0)$ & $<0,01^{*}$ \\
Delegacia Especializada/ DECCI & $486(20,4)$ & $1.431(48,0)$ & \\
Outros atendimentos & $928(38,9)$ & & \\
Outros atendimentos & & $464(32,4)$ & $<0,01^{*}$ \\
Visitas domiciliares & $155(16,7)$ & $252(17,6)$ & \\
Mediação de conflitos & $127(13,7)$ & $30(2,1)$ & \\
Avaliação psicológica & $59(6,4)$ & $58(4,1)$ & $627(43,8)$ \\
Visitas técnicas & $18(1,9)$ & $569(61,3)$ & \\
Sem informação & $569)$ & \\
\hline
\end{tabular}

Teste qui-quadrado de Pearson; *p-valor<0,05. DPE: Defensoria Pública do Estado; DECCI: Delegacia Especializada de Crime contra o Idoso; Fonte: Sistema de Informações Governamentais do Amazonas (e-SIGA). 


\section{DISCUSSÃO}

O presente estudo apontou um aumento do número de atendimentos de casos de violência intrafamiliar contra idosos no primeiro ano de pandemia de COVID-19 em Manaus ao se comparar com o ano de 2019. O número de casos diminuiu drasticamente nos meses de abril e maio de 2020, demonstrando o impacto dos decretos governamentais de isolamento social nos registros e atendimentos dessas vítimas. Além disso, constatouse que o número de atendimentos do CIPDI duplicou nos últimos três meses do ano de 2020 quando confrontados com o ano anterior, onde ainda não se tinha o contexto de pandemia declarado.

Moraes et al. ${ }^{9}$ afirmam que no contexto da pandemia, ou mesmo fora dela, os idosos são um dos grupos mais vulneráveis ao problema em função de um conjunto de motivos, dentre os quais destaca-se a habitual discriminação social ao envelhecimento e a insuficiência de políticas públicas de garantia de direitos ou em função da perda de poder aquisitivo das famílias no contexto de crise econômica desencadeada pela pandemia. Somando-se a isso, muitas vítimas de violência familiar podem estar enfrentando atualmente o "pior cenário", pois ficar presas em casa com um agressor violento durante um período de contato severamente limitado com o mundo exterior, provavelmente podem propiciar essas ações ${ }^{11}$.

A subnotificação dos casos de violência contra os idosos nesse contexto é uma realidade, ao se considerar a limitação dos atendimentos frente aos decretos governamentais de distanciamento social e o fato de que muitos idosos podem nunca ter conseguido atendimento para as violências sofridas. De acordo com Ricca e Oliveira ${ }^{12}$ apesar da existência do amparo legal ao idoso vítima de maus tratos, devido ao fato dos agressores em geral serem familiares, proporciona conflitos relacionados ao afeto, dependência ao idoso em denunciá-los aos órgãos de direitos humanos e policiais, contribuindo diretamente para a não notificação dos casos de violência contra a pessoa idosa no âmbito familiar.

De um modo geral, as variáveis que caracterizavam as vítimas, as ocorrências e os atendimentos analisadas apresentaram diferenças significativas ao compararse o contexto de pandemia e o ano de 2019. Os atendimentos analisados mostram que a maior parte das violências contra os idosos foi perpetrada contra mulheres. Esse dado corrobora a maioria dos achados de outros estudos nacionais, que apontam que a mulher idosa, é duplamente fragilizada, em função das circunstâncias do envelhecimento, pois em geral são mais doentes do que os homens e possuem, inclusive, mais incapacidades funcionais ${ }^{13}$. No que se refere à faixa etária dos idosos atendidos, verifica-se que o maior número de registros de denúncia ocorreu entre os 60 e 80 anos, reforçando os achados de Pampolim et al. ${ }^{14}$.

Outro ponto em destaque, são os idosos viúvos, com maior predominância no atendimento do CIPDI. A ausência de um companheiro é apontada como fator potencialmente associado a situações de negligência em idosos ${ }^{15}$. Tal característica, corrobora com os achados referentes a uma das principais tipologias de violência perpetrada contra os idosos neste estudo. Principalmente em função da dependência de outras pessoas da família e o quanto essas perdas podem torná-los frágeis a ponto de sentirem incapacitados de realizarem o próprio autocuidado.

Também se observou uma baixa escolaridade entre os idosos atendidos pelo CIPDI. Nóbrega et al. ${ }^{16}$ reforçam que o fato de o idoso não ser escolarizado está associado ao aumento na probabilidade deste sofrer violência e as implicações em decorrência da baixa escolaridade dificulta o acesso a informações sobre formas de prevenir as violências ou de resolver problemas. Houve a predominância de idosos aposentados ou que recebem algum tipo de benefício. Em estudo de Freitas et al. ${ }^{15}$ identificou-se ser a renda fixa dos idosos o principal fator motivador de maus-tratos. Quanto a maioria dos idosos se autodeclararem pardos, Souza et al. ${ }^{17}$ mostram que os idosos de cor preta e parda são os mais vulneráveis à violência, por existir uma construção social de exercício de dominação-exploração em relação aos pretos, fruto da herança escravocrata, que traz consigo o preconceito e a discriminação.

O local de procedência predominate entre os idosos atendidos no centro apontam para o destaque 
das zonas Norte e Sul, respectivamente. Tal achado se deve ao fato de a zona Norte ser a região com o maior número de habitantes da capital amazonense e a região Sul corresponder a zona de localização do próprio CIPDI.

Em Manaus, durante o ano de 2019 e no primeiro ano de pandemia de COVID-19, tanto a intimidação/ perturbação quanto a negligência foram as mais frequentemente registradas entre os atendimentos do centro de defesa e proteção. O predomínio da negligência/abandono e da intimidação/perturbação como violência psicológica reafirma os achados de Lopes e D'Elboux ${ }^{18}$ em estudo realizado com base nas notificações de violência contra a pessoa idosa em Campinas, São Paulo, nos últimos 11 anos.

Ainda no contexto de pandemia, a ocorrência de violências intrafamiliares mais graves como agressão física e ameaça de morte e não identificadas no ano de 2019, corroboram com Carmo et al. ${ }^{19}$ sobre a tendência crescente da mortalidade por causas externas em idosos no Brasil e em diferentes regiões brasileiras, principalmente nas regiões Norte, Nordeste e Centro-oeste. Conforme o Manual de Enfrentamento à Violência contra a Pessoa Idosa ${ }^{20}$ a natureza da violência contra a pessoa idosa pode se manifestar de várias formas e todos esses tipos de ação ou omissão podem provocar lesões graves físicas, emocionais e morte. O Estatuto do Idoso ${ }^{4}$ destaca que nenhum idoso será objeto de qualquer tipo de negligência, discriminação, violência, crueldade ou opressão, e todo atentado aos seus direitos, por ação ou omissão, será punido na forma da lei.

Quanto às características do agressor e os parentescos com os idosos, os resultados deste estudo são similares aos de outras pesquisas ${ }^{21-23}$, ao revelarem que o principal agressor é membro da família, destacando-se os filhos dos idosos os principais denunciados e estavam sob efeito de álcool ou outras drogas no momento da agressão. Ressaltase que frequentemente, o idoso tem dificuldade de denunciar o agressor por diferentes motivos, um deles é por ser membro da família, a vítima constantemente insiste em defender e justificar as atitudes do seu agressor com medo de prejudicar ou de que a situação entre eles possa se agravar com a denúncia. Minayo e Souza ${ }^{5}$ esclarecem que normalmente os agressores vivem na casa com a vítima, são filhos dependentes do idoso e o idoso dependente dos familiares. Filhos ou idosos que abusam de álcool e drogas, pertencem a famílias pouco afetivas ao longo da vida e isoladas socialmente.

$\mathrm{O}$ atendimento direcionado aos idosos vítimas de violência intrafamiliar realizados pelo CIPDI mostrou que em mais de $60 \%$ dos casos registrados necessitaram de encaminhamentos a outros pontos da rede de proteção ao idoso, em especial a delegacia especializada de crime contra o idoso, denotando a necessidade de uma rede de atendimento que seja articulada e de pronto atendimento a vítima. Wanderbroocke ${ }^{24}$ afirma que uma rede de proteção não pode ser considerada boa ou ruim com base apenas em seu tamanho, mas que há de se levar sempre em conta as demais características, como a densidade, composição, dispersão e tipos de função desempenhada pelos integrantes. É na confluência de suas características que se pode estabelecer sua capacidade em ser fonte de bem-estar.

Alguns atendimentos externos presenciais realizados pelo centro apresentaram aumento em 2020, demonstrando o possível impacto do novo coronavírus e a necessidade de decretação do cancelamento temporário dos serviços ofertados a essa população em diversos setores e a necessidade de se levar o atendimento ao domicílio dos idosos. Grilo e Lombardi Junior ${ }^{25}$ enfatizam que a prevenção e a intervenção devem ser realizadas juntamente aos idosos que sofreram maus-tratos, pois além de desenvolver estratégias para encorajar as vítimas a falar sobre os episódios vivenciados, os atendimentos desses profissionais possibilitam a conscientização destes sobre a violência e como esta pode interferir no envelhecimento, que deve ser seguro e digno.

A despeito das limitações encontradas, aponta-se as inerentes a uma pesquisa com dados secundários, na qual os pesquisadores têm pouco controle sobre os dados usados para a elaboração dos relatórios que serviram de fonte das informações, além da ausência de algumas informações que tornassem possível descrever em detalhes o perfil das vítimas, dos agressores e dos atendimentos realizados pelo centro. 


\section{CONCLUSÃO}

Os resultados encontrados neste estudo evidenciam que, no município de Manaus, a violência intrafamiliar contra a pessoa idosa apresentou aumento significativo após a declaração da Organização Mundial de Saúde de pandemia pelo novo coronavírus. As diferenças identificadas quanto ao perfil dos idosos atendidos reforça o quanto os decretos estaduais para garantia do distanciamento social e controle da disseminação da doença apresentaram impacto sobre o registro das ocorrências desse tipo de violência, demandando a intensificação da realização de visitas domiciliares e técnicas. Além disso, o número das ocorrências dessas violências pode ter sido muito maior do que o oficialmente registrado, configurando-se em subnotificação dos casos em decorrência da dificuldade em acessar aos serviços ofertados pelo centro integrado durante esse período.

Conhecer o perfil dos idosos vítimas de violência intrafamiliar atendidos pelo CIPDI, das ocorrências e dos possíveis agressores pode contribuir com estudos futuros nessa área além de subsidiar o planejamento das ações do próprio centro e de outras políticas públicas de proteção da pessoa idosa na capital do Amazonas diante da constatação da transição demográfica que ocorre em todos os estados do Brasil e da importância da oferta desses serviços como principal forma de intervir no ciclo da violência.

Dessa forma, conclui-se que se torna essencial disponibilizar às pessoas idosas, uma rede de serviços integral capaz de assegurar a toda essa população, os direitos básicos, como: saúde, transporte, lazer, ausência de violência tanto no espaço familiar como no espaço público. O cenário de pandemia tornou a população idosa mais vulnerável e exposta às violências intrafamiliares e os limitou quanto aos direitos constitucionais. Nesse contexto, o Centro Integrado de Proteção e Defesa dos Direitos da Pessoa Idosa por meio dos serviços ofertados caracteriza-se como política pública necessária para o acesso ao sistema de garantias de direito que visam além de prevenção, enfrentamento e efetivação dos direitos da pessoa idosa. Espera-se que este trabalho impulsione a realização de novos estudos, dedicados a explorar outras possibilidades de análise do tema.

Editado por: Tamires Carneiro de Oliveira Mendes

\section{REFERÊNCIAS}

1. Brito F. Transição demográfica e desigualdades sociais no Brasil. Rev Bras Est Popul. 2008;25(1):5-26.

2. DATASUS: Departamento de Informática do SUS [Internet]. Brasília, DF: DATASUS; 1991- . Informações de Saúde, Demográficas e Socioeconômicas; [acesso em 16 ago. 2021]; [2 telas]. Disponível em: http://tabnet.datasus.gov.br/cgi/ tabcgi.exe?popsvs/cnv/popbr.def

3. Travassos GF, Coelho AB, Arends-Kuenning MP. The elderly in Brazil: demographic transition, profile, and socioeconomic condition. Rev Bras Est Popul. 2020;37:1-27.

4. Brasil. Lei No 10.741 , de $1^{\circ}$ de outubro de 2003. Dispõe sobre o Estatuto do Idoso e dá outras providências. Portal da Legislação. 2003. Disponível em: http:// www.planalto.gov.br/ccivil_03/leis/2003/110.741.htm .

5. Minayo MCS, Souza ER. Violência contra idosos: é possível prevenir. In: Brasil. Ministério da Saúde. Impacto da violência na saúde dos brasileiros. Brasília, DF: MS; 2005. p.141-166.

6. Krug EG, Dahlberg LL, Mercy JA, Zwi AB, Lozano $\mathrm{R}$. World report on violence and health. Geneva: WHO; 2002.

7. Brasil. Ministério da Saúde, Secretaria de Políticas de Saúde. Violência intrafamiliar: orientações para prática em serviço. Brasília, DF: Ministério da Saúde; 2001.

8. Vieira PR, Garcia LP, Maciel ELN. Isolamento social e o aumento da violência doméstica: o que isso nos revela? Rev Bras Epidemiol. 2020;23:E200033.

9. Moraes CL, Marques ES, Ribeiro AP, Souza ER. Violência contra idosos durante a pandemia de Covid-19 no Brasil: contribuições para seu enfrentamento. Ciênc Saúde Colet. 2020;25(supl. 2):4177-84.

10. Miranda GMD, Mendes ACG, Silva ALA. Desafios das políticas públicas no cenário de transição demográfica e mudanças sociais no Brasil. Interface. 2017;21(61):309-20. 
11. Campbell AM. An increasing risk of family violence during the Covid-19 pandemic: strengthening community collaborations to save lives. Forensic Sci Int. 2020; 2:100089.

12. Ricca AETO, Oliveira B. Desvelando Caminhos: A subnotificação de acidentes e violência contra a pessoa idosa. Rev Port Divulg. 2012;23:64-76.

13. Pasinato MT, Camarano AA, Machado L. Idosos vítimas de maus-tratos domésticos: estudo exploratório das informações levantadas nos serviços de denúncia. Rio de Janeiro: IPEA; 2006. p.1-36.

14. Pampolim G, Pedroso MRO, Leite FMC. Análise dos casos notificados de violência física contra a pessoa idosa no Espírito Santo. Estud Interdiscip Envelhec. 2020;25(2):97-218.

15. Freitas MC, Queiroz TA, Sousa JAV. O significado da velhice e da experiência de envelhecer para os idosos. Rev Esc Enferm USP. 2010; 44(2):407-12.

16. Nóbrega IRAP, Leal MCC, Marques APO, Vieira JCM. Fatores associados à depressão em idosos institucionalizados: revisão integrativa. Saúde Debate. 2015;39(105):536-50.

17. Souza AS, Meira EC, Neri IG, Silva JA, Gonçalves LHT. Fatores de risco de maus-tratos ao idoso na relação idoso/cuidador em convivência intrafamiliar. Textos Envelhecimento. 2004; 7(2):1-14.

18. Lopes EDS, D’Elboux MJ. Violência contra a pessoa idosa no município de Campinas, São Paulo, nos últimos 11 anos: uma análise temporal. Rev Bras Geriatr Gerontol. 2021;24(6):e200320.
19. Carmo EA, Souza TS, Nery AA, Vilela ABA, Martins Filho IE. Tendência da mortalidade por causas externas em idosos. Rev Enferm UFPE on line. 2017;11(supl.1):374-83.

20. Brasil. Secretaria de Direitos Humanos da Presidência da República. Manual de enfrentamento à violência contra a pessoa idosa. É possível prevenir. É necessário superar. Brasília, DF: SDHPR; 2014.

21. Lopes EDS, Ferreira AG, Pires CG, Moraes MCS, D’Elboux MJ. Maus-tratos a idosos no Brasil: uma revisão integrativa. Rev Bras Geriatr Gerontol. 2018;21(5):652-62.

22. Pampolim G, Leite FMC. Negligência e violência psicológica contra a pessoa idosa em um estado brasileiro: análise das notificações de 2011 a 2018. Rev Bras Geriatr Gerontol. 2020;23(6):e190272.

23. Bolsoni CC, Coelho EBS, Giehl MWC, D’Orsi E. Prevalência de violência contra idosos e fatores associados, estudo de base populacional em Florianópolis, SC. Rev Bras Geriatr Gerontol. 2016;19(4):671-82.

24. Wanderbroocke ACNS. Idosas, rede social significativa e o enfrentamento da violência familiar. Estud Interdiscip Envelhec. 2017;22(1):99-116.

25. Grilo PMS, Lombardi Jr. I. Maus-tratos a idosos: perfil das vítimas, vínculo com o agressor e atuação dos profissionais. Estud Interdiscip Envelhec. 2015;20(2):611-24. 